\title{
DESENVOLVIMENTO DE UMA TIPOLOGIA HIDROGEOMORFOLÓGICA DE NASCENTES BASEADA EM ESTATÍSTICA NEBULOSA MULTIVARIADA
}

\section{DEVELOPMENT OF A HYDROGEOMORPHOLOGICAL TYPOLOGY OF RIVER SPRINGS BASED ON MULTIVARIATE FUZZY STATISTICS}

\author{
Miguel Fernandes Felippe \\ Departamento de Geociências, Universidade Federal de Juiz de Fora. \\ Rua José Lourenço Kelmer, s/n - Campus Universitário, Juiz de Fora/MG, Cep: 36036-900, Brasil. \\ E-mail: miguel.felippe@ufjf.edu.br \\ Antônio Pereira Magalhães Junior \\ Departamento de Geografia, Universidade Federal de Minas Gerais. \\ Av. Antônio Carlos, 6627 - Pampulha - Belo Horizonte/MG, Cep: 31270-901, Brasil. \\ E-mail: magalhaesufmg@yahoo.com.br
}

Informações sobre o Artigo

Data de Recebimento:

$16 / 10 / 2013$

Data de Aprovação:

$21 / 06 / 2014$

Palavras-chave:

Nascente; Hidrogeomorfologia; Conjuntos Nebulosos; Gestão.

\section{Keywords:}

Spring; Hydrogeomorphology; Fuzzy Sets; Management.

\section{Resumo:}

As nascentes de cursos d'água são sistemas hidrogeomorfológicos complexos, caracterizados por uma grande variabilidade de seus elementos estruturantes. Esta heterogeneidade ainda pouco conhecida cria dificuldades para os processos de gestão ambiental, pois, em teoria, cada nascente responde a perturbações de maneira diferente. Nesse sentido, este trabalho tem como objetivo desenvolver uma tipologia de nascentes com base em suas características hidrogeomorfológicas que sistematize sua heterogeneidade, sem perder seus aspectos individuais. Para atingir esta meta um método de máxima verossimilhança baseado na teoria dos conjuntos nebulosos foi usado para criar perfis multivariados para 79 nascentes catalogadas em três parques urbanos de Belo Horizonte - MG. Após uma série de testes estatísticos, propuseram-se seis tipos básicos no qual as nascentes podem ser enquadradas. No entanto, o principal avanço desta técnica é permitir a comparação entre os diferentes graus de pertencimento de cada nascente em cada tipo criado, auxiliando na compreensão da sua diversidade, sem esconder a sua heterogeneidade.

\footnotetext{
Abstract:

The river springs are complex hydrogeomorphological systems characterized by a great variability of their structuring elements. This unfamiliar heterogeneity creates difficulties for the environmental management processes, because theoretically each spring answers to disturbs in different way. Thus, this work aims to develop a typology for river springs based on their hydrogeomorphological characteristics that can systematize their heterogeneity without losing individual aspects. To
} 
accomplish the goal, a maximum likelihood method based on the fuzzy sets theory was used to create multivariate profiles for 79 river springs cataloged in three urban parks of Belo Horizonte - MG. After a series of statistical tests, it was proposed six basic types in which the river springs can be framed. Nevertheless, the main advance of this technique is to allow the comparison of the different grades of membership of each spring in each created type, assisting the comprehension of their diversity without hide their heterogeneity.

\section{Introdução}

A busca pela elaboração de tipologias tem como finalidade evidente a sistematização do conhecimento científico. Agrupar um rol de objetos de estudo segundo características comuns facilita o entendimento sobre a sua natureza e o seu comportamento, permitindo a continuidade dos estudos de forma mais organizada e direcionada, já que se conhece, de antemão, as similaridades existentes entre os indivíduos do mesmo grupo.

Essa discussão torna-se essencialmente importante em estudos de nascentes de cursos d'água. Conceitualmente, "considera-se uma nascente como um sistema ambiental em que o afloramento da água subterrânea ocorre naturalmente de modo temporário ou perene, integrando à rede de drenagem superficial" (FELIPPE, 2009, p. 99). Sendo assim, há uma grande heterogeneidade fisiográfica nesses sistemas, que reflete a influência de características ambientais locais e regionais. Este artigo tem como objetivo desenvolver uma tipologia para nascentes, baseada em parâmetros hidrogeomorfológicos, a partir de uma metodologia de vanguarda. Espera-se que os resultados deste trabalho possam contribuir para a ampliação do conhecimento científico sobre as nascentes, bem como, para a melhoria das ações de gestão ambiental que, atualmente, desconsideram a heterogeneidade desses sistemas.

A literatura especializa apresenta algumas propostas de tipologias ou classificações, na tentativa de sistematizar as heterogeneidades intrínsecas às nascentes. A maioria, porém, tem como principal limitação basear-se apenas em um critério de classificação (monovariadas), ou seja, em apenas uma das incontáveis características ambientais das nascentes, o que limita sobremaneira sua utilização.

Esse é o caso da tipologia provavelmente mais simples e amplamente utilizada, associada aos estudos fluviais, em que as nascentes são enquadradas segundo as variações sazonais em perenes ou temporárias (VALENTE; GOMES, 2005; CHRISTOFOLETTI, 1981); e da proposta de Meinzer (1927) que se baseia na vazão média anual das nascentes. Além disso, podem-se citar inúmeras outras propostas que preconizam apenas uma característica das nascentes para classificá-las: quanto à mobilidade na vertente, as nascentes podem ser fixas ou móveis (FARIA, 1997); quanto à energia envolvida nos fluxos subterrâneos, podem ser artesianas ou freáticas (VALENTE; GOMES, 2005) ou gravitacionais e não-gravitacionais (BRYAN, 1919 apud TODD, 1959). Todas essas tipologias são baseadas no conceito de bivalência (ou uma nascente está inserida em um tipo ou não está e, portanto, insere-se em outro tipo) baseado naquilo que é chamado de teoria clássica dos conjuntos (HARRIS, 1999).

Ampliando a discussão, dois trabalhos são de grande relevância para o estudo de tipologias de nascentes no Brasil: Faria (1997) e Valente e Gomes (2005). Esses estudos apresentam um avanço considerável ao não se limitar à utilização de apenas uma variável, cruzando algumas características das nascentes para elaboração dos agrupamentos. Todavia, esses trabalhos apresentam uma série de imprecisões que acarretam na baixa aplicabilidade de suas proposições. O principal problema encontrado é estritamente metodológico: em ambos os casos o grau de subjetividade dos tipos criados é extremamente grande, não sendo descrito o encadeamento metodológico que levou à tipologia. Destarte, é extremamente complexo enquadrar uma nascente em algum tipo dos propostos seja por Faria (1997) ou Valente e Gomes (2005), devido à falta de critérios objetivos para tal. Além disso, há uma série de nascentes que não se enquadram em quaisquer dos tipos criados.

O desafio que se posta é, então, o de elaborar uma tipologia que, apesar de baseada em um grupo de nascentes que foi estudado, possibilite a utilização dos agrupamentos criados em outras circunstâncias ambientais. É necessário, então, buscar uma metodologia que permita, simultaneamente, a interpretação multivariada e qualitativa das nascentes, além de contemplar a sua conhecida complexidade e diversidade. O método Grade of Membership (GoM) enquadra-se, então, nas exigências teóricas da proposta. Baseado na Teoria dos 
Conjuntos Nebulosos, ele permite a análise multivariada qualitativa, agrupando os objetos de estudo a partir de um modelo de máxima verossimilhança (CERQUEIRA, 2004; GARCIA et al., 2004; HARRIS, 1999; MANTON et al., 1994).

Ainda muito pouco explorado pelas ciências ambientais, o GoM tem sido muito utilizado nas ciências médicas para a determinação de grupos de suscetibilidade a enfermidades e na construção de condicionantes para doenças (MANTON et al., 1994). No Brasil, sua utilização é mais comum na demografia (SATHLER, 2009; CERQUEIRA, 2004; GARCIA et al., 2004), enquanto nas ciências ambientais acredita-se que os primeiros trabalhos brasileiros a utilizar o GoM tenham sido de Felippe et al. (2009) e Felippe e Magalhães Jr. (2013).

Os procedimentos estatísticos clássicos nem sempre se apresentaram satisfatórios nas ciências ambientais, incluindo a geomorfologia. A exigência de quantificação dos fenômenos por esses métodos dificulta a utilização de uma série de informações que são, em princípio, qualitativas. Na opinião de Manton et al. (1994), o desgaste dos métodos estatísticos tradicionais e a insolubilidade de problemas com as técnicas clássicas, levaram Zadeh (1965 apud MANTON et al, 1994) a propor uma nova lógica matemática que não presumisse a bivalência do verdadeiro ou falso, permitindo o estabelecimento de respostas entre esses dois extremos. Os novos conceitos apresentados por Zadeh (1965 apud HARRIS, 1999) basearam a formulação da Teoria dos Sistemas Nebulosos, que preconiza o raciocínio impreciso e a análise qualitativa. "A teoria foi postulada com a finalidade de processar informações subjetivas, de natureza vaga e incerta, da linguagem natural, possibilitando a modelagem de conceitos subjetivos" (HARRIS, 1999. p. 20).

$\mathrm{Na}$ matemática clássica o pertencimento de um elemento a um determinado conjunto é absoluto: ou o elemento pertence ou não (bivalência). Na matemática nebulosa, os limites dos conjuntos não são definidos com precisão e a inclusão de um elemento é definida por uma função que expressa o seu grau de pertencimento ao conjunto. Assim, um elemento pode pertencer parcialmente a múltiplos conjuntos, apresentando, para cada um destes, um grau de pertinência passível de determinação.
Pertencimento para os conjuntos tradicionais requer que cada elemento individualmente seja membro de um conjunto - ou não. Dois conjuntos são disjuntos se não apresentam elementos em comum. Nos conjuntos nebulosos, um elemento pode ser um membro parcial de múltiplos conjuntos (MANTON et al., 1994. p. 3).

Sob esses preceitos está o GoM. Desenvolvido por Manton et al. (1994), é um método de estimação estatística de máxima verossimilhança que se baseia na teoria dos conjuntos nebulosos em que um mesmo elemento pode se inserir, simultaneamente, em diversos conjuntos e apresentar graus de pertencimento distintos em relação a esses (CERQUEIRA, 2004; GARCIA et al., 2004).

Cada elemento possui um escore de pertencimento que o relaciona a um determinado perfil, seja uma tipologia ou uma classificação. A soma dos escores de um mesmo elemento para seus diversos perfis é 1. Os procedimentos estatísticos, então, convergem para o agrupamento dos elementos mais parecidos em determinados conjuntos. Entretanto, essa pertinência não está relacionada à probabilidade de inclusão do elemento em determinado conjunto nebuloso; por princípio o elemento que possui grau de pertinência superior a zero já está incluso - ao menos parcialmente - no conjunto (MANTON et al., 1994).

O método Grade of Membership (GoM) (...) lida com dois dos maiores problemas na determinação de uma classificação ou tipologia, que são a identificação de grupos e a descrição de diferenças entre os mesmos (CERQUEIRA, 2004).

Assim, a definição de escores GoM para cada unidade de estudo permite a representação da heterogeneidade entre as mesmas, dentro de cada perfil gerado. Essa característica coloca vantagens comparativas do GoM em relação às metodologias mais comuns como a Análise de Cluster e a Análise Discriminante, que apresentam problemas com a heterogeneidade dos indivíduos. Todavia, o GoM lida com o agrupamento e a estimação de 
coeficientes de pertencimento simultaneamente, o que é um avanço metodológico considerável (CERQUEIRA, 2004). Destarte, ao gerar agrupamentos dos elementos em função da proximidade de suas características por máxima verossimilhança, o GoM permite a construção de tipologias (ALVES et al., 2008; CERQUEIRA, 2004; MANTON et al., 1994).

A técnica GoM estima, com base em um modelo de probabilidade multinomial, dois tipos de parâmetros: um de associação, $g_{i k}$, outro de estrutura, $l_{k j l}$, ou seja, os graus de pertinência (g) de cada elemento (i) a cada subconjunto, ou perfil, ou tipo ( $k$ ); e as probabilidades de cada categoria (l) de cada variável (j) em cada perfil ( $k$ ) que, por sua vez, define esse perfil (GARCIA et al., 2004. p. 4).

Permitindo a identificação de grupos com características similares, é possível avançar na explicação de fenômenos complexos. No caso específico deste trabalho, a busca por uma tipologia de nascentes pode refletir em uma compreensão mais ampla sobre os processos envolvidos na descarga subterrânea, bem como em um entendimento mais preciso sobre o comportamento hidrogeomorfológico dessas feições.

\section{2. Área De Estudo}

A dinâmica das nascentes é condicionada pelos elementos naturais e sociais do meio, bem como pela maneira com que estes se organizam no espaço. Sendo assim, espera-se ser notória a distinção existente entre as características das nascentes encontradas em diferentes domínios de paisagem, sejam estes estritamente naturais ou mesmo sociais. Nesse sentido, devido à diversidade fisiográfica de seu sítio, Belo Horizonte configura-se como uma importante área para tais estudos.

O clima de Belo Horizonte é sub-quente semiúmido, com médias térmicas entre 15 e $18^{\circ} \mathrm{C}$ em pelo menos um mês e 4 a 5 meses secos (IBGE, 2002). A dupla estacionalidade climática é marcante. Entre os meses de outubro e março, as temperaturas médias são mais elevadas, assim como os índices pluviométricos. Por conseguinte, a umidade do ar também é elevada em detrimento da evaporação, que apresenta os menores va- lores anuais. No semestre subsequente - abril a setembro - há uma considerável queda nas temperaturas médias e na umidade; as chuvas são praticamente inexistentes e a evaporação aumenta consideravelmente.

O sítio de Belo Horizonte se encontra na borda sul do cráton do São Francisco, em contato com o Cinturão Móvel Neoproterozóico do Quadrilátero Ferrífero (SHOBBENHAUSS, 1984). Essa configuração morfoestrutural promove a existência da Depressão de Belo Horizonte - parte sul da Depressão do Alto-Médio São Francisco - e das Serras do Quadrilátero Ferrífero (IBGE, 2006), unidades do relevo nas quais se insere a metrópole.

As nascentes estudadas no município de Belo Horizonte localizam-se em três parques urbanos: Parque Municipal das Mangabeiras, Parque Municipal Fazenda Lagoa do Nado e Parque Primeiro de Maio (Figura 1). As unidades de conservação foram priorizadas para o estudo por configurarem espacialidades de menor alteração antrópica, onde as nascentes tendem a possuir maior equilíbrio ambiental. No interior dos parques, foram mapeadas as bacias hidrográficas que drenam as unidades, de modo que, buscou-se a identificação de todas as nascentes no interior dessas bacias, tornando possível, quando necessário, a segmentação do estudo na escala das bacias hidrográficas, conforme recomendação da legislação brasileira sobre os recursos hídricos.

O Parque Municipal das Mangabeiras, com uma área de $2.417 .000 \mathrm{~m}^{2}$, encontra-se na vertente norte da Serra do Curral - domínio do Quadrilátero Ferrífero - com cotas altimétricas variando entre 950 e 1.350 m. O extremo sudeste do Parque é marcado por uma linha de crista sustentada por concreções lateríticas que determina o divisor da drenagem e também o limite intermunicipal. A drenagem possui padrão dendrítico, por vezes, com nítido controle estrutural. Os canais de ordem zero situam-se nas altas vertentes, caracterizando-se por inúmeros ravinamentos profundos que se interligam à rede de drenagem perene na porção média da vertente. Os canais fluviais são encaixados, muitas vezes com talvegue em rocha sã, indicando incisão vertical intensa, o que promove baixa sinuosidade e a inexistência de planícies.

No substrato geológico predominam dolomitos e itabiritos dolomíticos da Formação Gandarela (Supergrupo Minas). As cristas da porção sudeste apresentam 


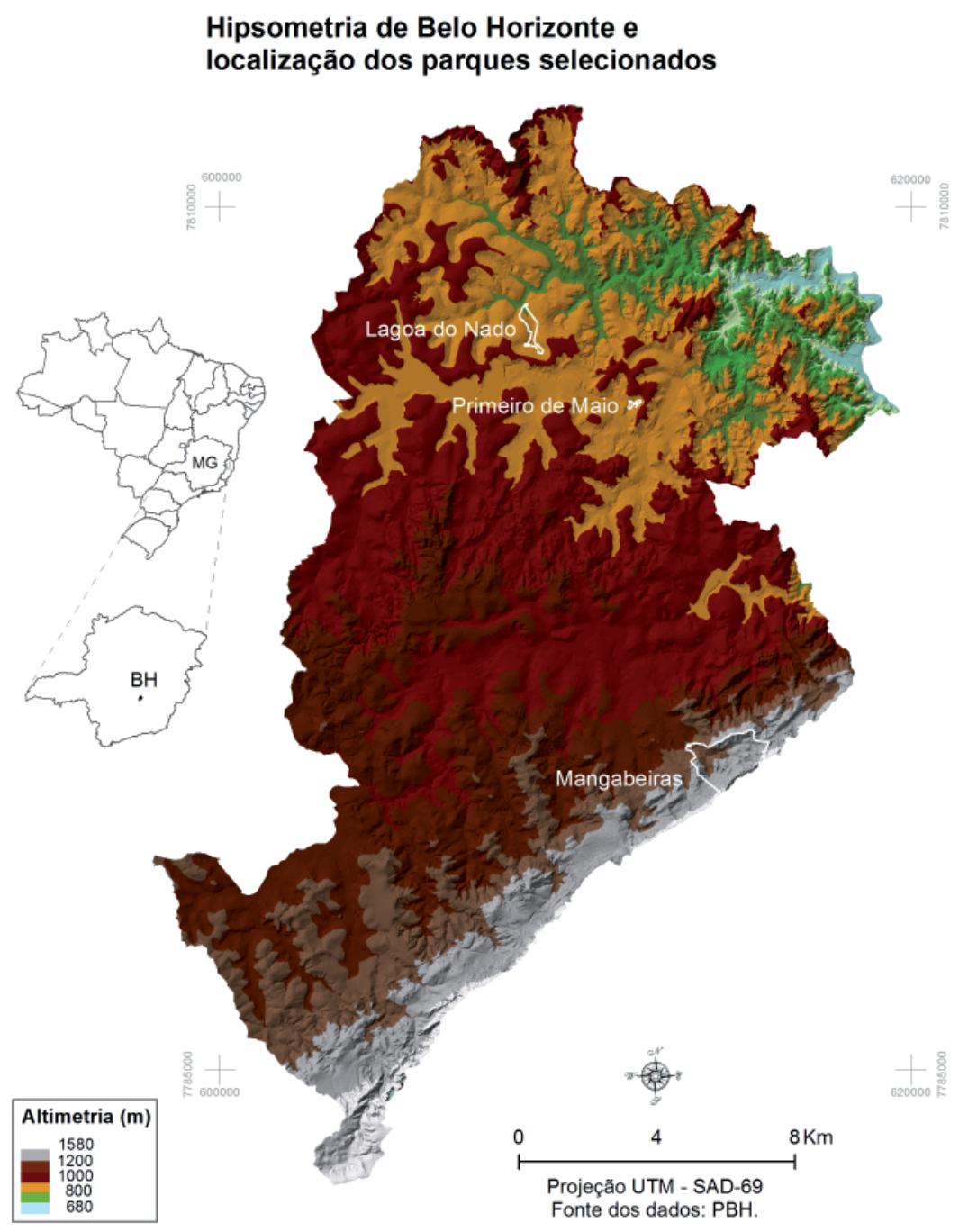

Figura 1 - Localização das unidades de estudo no município de Belo Horizonte.

crostas lateríticas - Canga - sobrepostas a itabiritos, filitos e dolomitos da Formação Cauê (CPRM, 2000).

O Parque Municipal Fazenda Lagoa do Nado possui área total de $307.000 \mathrm{~m}^{2}$. Morfologicamente, constitui-se de um vale fluvial de fundo chato, com vertentes suaves e declividade variando entre próximo a zero - na planície dos canais de drenagem - e superiores a $30^{\circ} \mathrm{em}$ alguns pontos isolados como cabeceiras de drenagem e rupturas de declive. As altitudes variam de aproximadamente $750 \mathrm{~m}$ na planície do Córrego do Nado, a pouco mais de 800 m nos interflúvios da bacia. A maioria dos canais possui fundo chato e é preenchida por sedimentos, com margens normalmente planas e sazonalmente alagadas.

A diversidade litológica encontrada no Parque das Mangabeiras não é verificada no Parque Lagoa do Nado
- domínio do embasamento cristalino. O vale do Córrego do Nado foi moldado nas rochas do Complexo Belo Horizonte (CPRM, 2000), destacando-se gnaisses e migmatitos indiscriminados, sem evidências de grandes descontinuidades físicas. Os mantos de intemperismo são espessos e alterados por sucessivos revolvimentos de origem antrópica.

O Parque Primeiro de Maio apresenta área total corresponde a $34.000 \mathrm{~m}^{2}$, aproximadamente $10 \%$ do tamanho do Parque Lagoa do Nado e menos de 1,5\% do tamanho do Parque das Mangabeiras. Assim como o Parque Lagoa do Nado, o Primeiro de Maio também se insere em um vale fluvial, com altitude variando entre $775 \mathrm{~m}$ e $800 \mathrm{~m}$, resultando em uma topografia suave. Todavia, a morfologia local sofreu marcante influência antrópica. $\mathrm{O}$ substrato geológico é consideravelmente 
homogêneo, constituído basicamente por gnaisses e migmatitos individualizados do Complexo Belo Horizonte, inserido no embasamento cristalino arqueano (CPRM, 2000). Não foram verificados afloramentos rochosos, devido à elevada espessura do manto de alteração nessa região. Ademais, as características pedológicas apresentam-se completamente descaracterizadas devido aos revolvimentos por ação antrópica.

\section{Materiais E Métodos}

\subsection{Identificação e mapeamento das nascentes}

A identificação das 79 nascentes estudadas foi realizada em atividades de campo que se orientavam seguindo a rede de drenagem (de jusante para montante) até que fosse verificado o local exato de exfiltração da água. Entretanto, devido à dupla estacionalidade climática da área de estudo, foram necessárias duas campanhas de campo: a primeira no período de excesso hídrico (entre novembro de 2008 e março de 2009) e a segunda no período de deficiência hídrica (entre junho e agosto de 2009). O principal motivo desse procedimento é o de evidenciar os comportamentos sazonais das nascentes, elucidando possíveis modificações hidrogeomorfológicas. Além disso, somente com a visita no período de estiagem pode-se garantir a classificação de um curso d'água como perene, intermitente ou efêmero.

Partindo-se de um prévio mapeamento da rede de drenagem e da experiência de funcionários dos parques foi percorrido um total aproximado de $177 \mathrm{~km}$ de trilhas para investigar, com o máximo de detalhe, a ocorrência de fontes. As surgências encontradas somente foram enquadradas conceitualmente como nascentes se respeitassem os critérios apresentados no conceito proposto por Felippe (2009).

Após a identificação das nascentes, foram coletadas suas coordenadas geográficas ( $\mathrm{x}, \mathrm{y}$ e $\mathrm{z}$ ) com $\mathrm{o}$ auxílio de um receptor GPS modelo Garmin GPSMAP 76CSx. Para reduzir eventuais imprecisões na coleta, realizou-se a média de três pontos subsequentes marcados exatamente no mesmo local, permitindo um erro inferior a $5 \mathrm{~m}$ de raio. $\mathrm{O}$ mapeamento foi concluído com a plotagem dos pontos coletados no software ArcGIS 9.3, em sobreposição com a base topográfica e hidrográfica $(1 / 2.500)$ obtida junto à Fundação de Parques Municipais da Prefeitura de Belo Horizonte.
3.2 Levantamento das características ambientais das nascentes

A elaboração de uma matriz de características ambientais baseia-se na premissa de que para compreender a dinâmica dos processos que configuram um sistema ambiental é necessário, em princípio, reconhecer os elementos que o constituem e o estruturam (TROPMAIR, 2004; PASSOS, 1988). Com isso, o estudo da paisagem e a verificação dos elementos físicos, biológicos e antrópicos que se interagem no espaço é essencial para a avaliação dos condicionantes ambientais das nascentes.

Os parâmetros escolhidos para compor a matriz foram aqueles relatados na bibliografia consultada como importantes para compreensão da dinâmica e tipologia das nascentes. As linhas da matriz correspondem às nascentes identificadas; as colunas correspondem às características levantadas de forma primária ou secundária, cujas principais são:

- ID: código identificador atribuído à nascente;

- $\quad X, Y$ e $Z$ : respectivamente, longitude, latitude e altitude da nascente (UTM-SAD 69);

- $p H$ : potencial hidrogeniônico da água das nascentes medido diretamente em campo com pHmetro. A medição foi realizada o mais próximo possível das nascentes, desde que a profundidade da lâmina d'água permitisse a inserção da sonda (aproximadamente $2 \mathrm{~cm}$ );

- Coliformes: número mais provável de coliformes totais e fecais encontrados na água das nascentes. A medição foi realizada por colipaper da AlfaKit;

- Si, Fe e Al: concentração de silício, ferro e alumínio, respectivamente, na água das nascentes nos períodos de verão e inverno. $\mathrm{O}$ método consistiu na coleta de amostras de água e posterior análise laboratorial em fotocolorímetro;

- Morfologia: padrão morfológico da nascente, verificado empiricamente em campo;

- Exfiltração: tipo de passagem da água subterrânea para a superfície;

- Contato: tipo de superfície de contato existente no local de exfiltração da água;

- Cabeceira: inserção (ou não) das nascentes em cabeceira de drenagem;

- Canal: inserção (ou não) das nascentes em canais de drenagem; 
- Largura, profundidade e área do setor: características morfométricas do canal (quando este existe) no qual se insere a nascente, medidas diretamente por trena;

- Área alagada: área ocupada pelo espelho d'água em nascentes que apresentam feições brejosas ou pequenos lagos, medida em campo por trena;

- Vazão: calculada em L/s no verão e no inverno, de forma direta através da coleta da água (mais próximo possível dos pontos ou áreas de exfiltração) em sacolas plásticas e posterior transferência para medidores volumétricos graduados, com medição do tempo em cronômetro digital ${ }^{1}$;

- Razão de vazão: relação matemática entre a vazão de verão e de inverno da nascente.

- Migração: distância entre a posição da exfiltração da nascente no verão e no inverno;

- Antropogenia: existência (ou não) de indícios de gênese antrópica da nascente;

- Vegetação: tipo e densidade da cobertura vegetal do entorno imediato da nascente;

- Manto de intemperismo: espessura mensurável do manto de intemperismo de cada nascente no verão e no inverno;

- IIAN: índice de impacto ambiental macroscópico em nascentes, adaptado de Gomes et al. (2005), que possibilita uma interpretação comparativa da qualidade ambiental e do grau de proteção das nascentes;

- Afloramentos rochosos: ocorrência (ou não) e posição dos afloramentos de rocha sã em relação à nascente, verificado empiricamente;

- Aspectos pedológicos: cor, textura e consistência de amostras superficiais de solo, obtidas por tradagem nas imediações das nascentes, de acordo com Santos et al. (2005);

- Usos (usos do solo e da água): tipo de usos antrópicos nas nascentes, verificado empiricamente e via entrevistas informais com funcionários dos parques;

- Impactos ambientais: estágio de degradação refletido em transformações ambientais nas proximidades das nascentes estudadas, verificado empiricamente e com o auxílio de entrevistas com funcionários dos parques;
- Substrato geológico: formação geológica na qual se insere a nascente. Obtido de forma secundária a partir das informações de Silva et al. (1995), na escala de 1/25.000;

- Estrutura geológica: existência (ou não) de grandes lineamentos estruturais nas proximidades das nascentes, segundo mapeamento de Silva et al. (1995), na escala de 1/25.000;

- Declividade: classe de declividade da vertente na qual se insere a nascente. Obtido pelo Modelo Digital de Terreno gerado a partir de curvas de nível de equidistância de um metro, fornecidas pela $\mathrm{PBH}$ (escala 1/25.000).

\subsection{Execução do método Grade of Membership}

Inicialmente, para a utilização do GoM, é necessário selecionar as variáveis (j) a serem utilizadas e elaborar a matriz qualitativa. Como não há trabalhos de referência para a tipologia multivariada de nascentes, iniciou-se uma fase de testes para determinação do número de tipos (k) a serem criados. Em cada um dos resultados, analisou-se sua capacidade de explicação ao verificar o grau de pertencimento de cada nascente a cada perfil criado $\left(\mathrm{g}_{\mathrm{ik}}\right)$ e também a probabilidade de cada categoria de cada variável em cada perfil $\left(\lambda_{\mathrm{kjj}}\right)$. Esses resultados foram avaliados pelo princípio da parcimônia, o qual exige o maior grau de explicação dos resultados por um número mínimo de perfis e variáveis.

Assim, a partir da determinação aleatória $\operatorname{dos} \lambda_{\mathrm{kj}}$, os agrupamentos foram definidos pela função multinominial de máxima verossimilhança do método Grade of Membership, expressa pela Equação 1.

$$
\mathrm{L}_{(\mathrm{y})}=\Pi^{\mathrm{i}} \Pi^{\mathrm{j}} \Pi^{\mathrm{Lj}}\left(\Sigma \mathrm{g}_{\mathrm{ik}} \lambda_{\mathrm{kj}}\right)
$$

$\mathrm{Na}$ equação, g é o grau de pertinência; i é cada elemento; $\mathrm{k}$ é cada subconjunto, perfil ou tipo; 1 é a probabilidade de cada categoria; j é cada variável. Então, $g_{\mathrm{ik}}$ é o parâmetro de associação, $\lambda_{\mathrm{kjl}}$ é o parâmetro de estrutura (GARCIA et al, 2004).

As variáveis selecionadas para o GoM poderiam ser quaisquer dentre as utilizadas para elaboração da matriz (item 3.2). Assim, para a primeira etapa de testes

${ }^{1}$ Para minimizar os possíveis erros de coleta, foram feitas de três a cinco medições em cada nascente. A vazão é então calculada pela fórmula: $Q=\Sigma(v / t) / n$. Em que: $Q$ é a vazão média observada (1/s); $v$ é o volume de água (em litros); $t$ é o tempo (em segundos); e $n$ é o número de medições (PINTO et al., 2004). 
do GoM, selecionou-se 35 variáveis (Quadro 1).

Como o GoM somente trabalha com variáveis discretas, todas aquelas que eram quantitativas tiveram que ser discretizadas pelo método de quebra natural, inicialmente, em 5 classes. Além disso, agruparam-se as respostas de todas as variáveis - qualitativas ou quantitativas - em categorias segundo critérios teóricos de afinidade, para evitar que alguma variável pudesse ter muitas categorias, o que prejudicaria a explicabilidade do modelo. Nos primeiros testes, foram executados dez modelos pelo progra ma GoM 3.4, $\operatorname{com} \lambda_{\mathrm{kil}}$ aleatórios, porém, cada um com um número de perfis (tipos) diferente, variando entre três e doze.

$\mathrm{O}$ ajuste de cada resposta do modelo foi medido pela porcentagem de tipos puros resultantes, ou seja, de casos caracterizados por $\mathrm{g}_{\mathrm{ik}}$ igual a um. Em segundo lugar, verificou-se, também, a porcentagem de casos com $\mathrm{g}_{\mathrm{ik}}$ superior a 0,70 , considerados como bem explicados pelo modelo.

Por ter havido o mínimo de interferência na elaboração dos modelos, os ajustes encontrados foram, todos, considerados muito baixos, tendo os modelos explicado de forma satisfatória menos de $50 \%$ dos casos. Assim, pelo princípio da parcimônia, verificou-se que os modelos com cinco, seis e sete perfis foram os que apresentaram melhor ajuste e mais fácil interpretação.
Ficou, então, definido que os demais testes seriam realizados apenas para esses números de perfis, sendo desnecessário avaliar outras composições.

Após estipular o número de perfis a serem trabalhados nos modelos seguintes iniciou-se um processo de reelaboração da matriz qualitativa, com redefinição das variáveis. A partir dos resultados dos primeiros modelos, verificou-se que uma série de variáveis apresentava comportamento muito similar, indicando redundância. Desse modo, o número de variáveis foi reduzido a fim de simplificar a matriz, bem como a tipologia. Com essa nova matriz qualitativa, elaboraram-se três modelos. Porém, os ajustes permaneceram baixos, inviabilizando a utilização dos resultados.

Verificaram-se dois problemas relacionados à matriz que poderiam estar prejudicando o grau de explicação das respostas obtidas pelo GoM. O primeiro relacionava-se à categorização das variáveis. Com o agrupamento em muitas classes, havia uma heterogeneidade muito grande na distribuição dos casos, o que promovia resíduos que, ao final, configuravam-se como uma dispersão dos $\mathrm{g}_{\mathrm{ik}}$. Desse modo, a categorização das variáveis foi revista, reduzindo o número de classes, porém, mantendo-se o princípio da quebra natural para variáveis quantitativas e da similaridade para as quantitativas.

Quadro 1: Parâmetros selecionados para a primeira fase de testes do modelo de classificação

\begin{tabular}{|c|c|c|c|c|}
\hline Hidrogeoquímicos & Qualidade & Fisiográficos & Morfométricos & Hidrométricos \\
\hline $\begin{array}{l}\text { Alumínio (verão e } \\
\text { inverno) }\end{array}$ & Antropogenia & Afloramentos rochosos & Área Alagada & Razão de Vazão \\
\hline $\begin{array}{l}\text { Ferro (verão e } \\
\text { inverno) }\end{array}$ & $\begin{array}{l}\text { Coliformes } \\
\text { Termotolerantes }\end{array}$ & Cabeceira de drenagem & Área Setor & \multirow{9}{*}{$\begin{array}{l}\text { Vazão (média } \\
\text { anual) } \\
\text { Vazão (verão e } \\
\text { inverno) }\end{array}$} \\
\hline $\mathrm{pH}$ & Coliformes Totais & Contato lítico & Declividade & \\
\hline \multirow[t]{7}{*}{$\begin{array}{l}\text { Sílica (verão e } \\
\text { inverno) }\end{array}$} & $\begin{array}{l}\text { Índice de Impacto } \\
\text { Ambiental }\end{array}$ & Geologia & Largura do canal & \\
\hline & Salmonela & Migração da nascente & $\begin{array}{l}\text { Profundidade do } \\
\text { canal }\end{array}$ & \\
\hline & & Morfologia (verão e inverno) & & \\
\hline & & Ocorrência de canal & & \\
\hline & & $\begin{array}{l}\text { Profundidade do manto } \\
\text { de intemperismo (verão e } \\
\text { inverno) }\end{array}$ & & \\
\hline & & $\begin{array}{l}\text { Textura do solo } \\
\text { Tipo de exfiltração (verão e } \\
\text { inverno) }\end{array}$ & & \\
\hline & & Tipo de vegetação & & \\
\hline
\end{tabular}


O segundo problema estava centrado na variável antropogenia, já que em nenhum modelo essa variável essencial estava bem explicada. Verificou-se que isso ocorria devido ao fato dessa variável não guardar qualquer relação com as demais, ou seja, uma nascente criada pela ação do homem poderia possuir quaisquer características. Assim, nas respostas geradas pelo GoM, essa variável acabava dispersa em diversos grupos, apesar de ser do tipo booleana, o que, em princípio, deveria facilitar seu agrupamento.

Optou-se, então, pela retirada dessa variável da matriz. Porém, devido à sua significância, ela foi considerada como um primeiro elemento na chave de classificação. Ou seja, a priori, todas as nascentes que possuíam resposta positiva para a variável antropogenia foram excluídas do rol e agrupadas separadamente, como um primeiro tipo pré-determinado.

Por fim, após essas alterações uma nova e definitiva matriz foi elaborada (apresentada no item de resultados). $\mathrm{O}$ algoritmo foi executado, então, para cinco, seis e sete perfis, para a escolha daquele que apresentasse melhores ajustes. De uma forma geral, todas essas adaptações acarretaram em resultados extremamente satisfatórios, elevando a porcentagem de casos bem enquadrados pelas tipologias criadas. Contudo, os melhores resultados foram obtidos para a tipologia com cinco perfis.

\section{Resultados e Discussões}

\subsection{Tipo de nascentes propostos}

Os resultados obtidos com a última matriz testada apresentaram uma porcentagem de tipos puros elevada, $58,2 \%$ (37 casos com $\mathrm{g}_{\mathrm{ik}}$ igual a um e os nove casos antropogênicos retirados anteriormente). Considerando-se um $\mathrm{g}_{\mathrm{ik}}$ de 0,70 como um ponto de corte satisfatório para o ajuste das nascentes dentro dos perfis criados, $o$ ajuste sobe para $68,3 \%$. Ademais, como a Teoria dos Conjuntos Nebulosos pressupõe a fluidez dos elementos dentro dos conjuntos, assim, optou-se por formar perfis híbridos, que ocorrem quando a soma de $\mathrm{g}_{\mathrm{ik}}$ para dois perfis criados supera o ponto de corte estipulado $(0,70)$. Nesse contexto, ocorrem 29,1\% das nascentes. Assim, somando-se os casos "puros", com os "ajustados" e os "híbridos", tem-se um percentual de $97,4 \%$ das nascentes estudadas satisfatoriamente explicadas pelo modelo proposto.
A Tabela 1 apresenta a distribuição de $\lambda_{\text {kj1 }}$ resultante, indicando a probabilidade de cada categoria das variáveis se inserir em cada perfil (k) criado. Foram destacados os valores de $\lambda_{\mathrm{kjl}}$ acima de 0,70 , pois estes representam as categorias mais relevantes na explicação de um perfil.

A morfologia das nascentes foi uma das categorias com maior complexidade nos enquadramentos. As nascentes em concavidade podem estar em $\mathrm{k} 1$ ou $\mathrm{k} 4$, sendo que neste último, são exclusivas. As nascentes em duto aparecem nos perfis $\mathrm{k} 2$ e $\mathrm{k} 5$. As demais categorias são enquadradas, cada uma, em apenas um perfil. Por outro lado, a distribuição do tipo de exfiltração é consideravelmente mais simples. As nascentes pontuais podem constituir $\mathrm{k} 1, \mathrm{k} 2, \mathrm{k} 3$ ou $\mathrm{k} 5$, porém, nesses dois últimos perfis, essa é a única categoria encontrada. As nascentes difusas se enquadram em $\mathrm{k} 1 \mathrm{e} \mathrm{k} 4$, sendo que em ambos os casos, $\lambda_{\mathrm{kjl}}$ é elevado, demonstrando a predominância dessa categoria. Contudo, as nascentes múltiplas somente são encontradas no perfil k2.

Quanto à existência de contatos, as nascentes com algum tipo de contato predominam em k2 e k4, aparecendo com menos expressividade em $\mathrm{k} 3$. Já aquelas que não possuem contato, se inserem em k1 e k5 (onde são exclusivas) e também em $\mathrm{k} 3$.

As variáveis relacionadas à vazão também apresentam enquadramento complexo nos perfis criados. Nascentes de baixa vazão podem ser encontradas em qualquer perfil, sendo que são as únicas existentes em k3, além de predominantes em k1 e k4. As de vazão média são enquadradas em k1, k2, k4 e k5, sendo que neste último perfil, estas são as mais representativas. As nascentes de alta vazão foram alocadas em k1 e k2, porém, em ambos os perfis encontram-se associadas às demais categorias. Já as nascentes com razão de vazão baixa (o que indica aumento de vazão no inverno) são enquadradas somente em k2. A categoria de vazão relativamente estável é presente em k1, k2 e k4. As nascentes com razão de vazão entre 1,15 e 8,0 também se enquadram nesses mesmos perfis ( $\mathrm{k} 1, \mathrm{k} 2 \mathrm{e} \mathrm{k} 4)$. Por fim, a única categoria que se encontra exclusiva em algum perfil é a de razão de vazão acima de $8,0, \operatorname{com} \lambda_{\text {kjl }}$ igual a um em k3 e k5, além de também se enquadrar em k1.

Todavia, a migração foi uma variável bem explicada. As nascentes fixas foram alocadas em k1 e k2, sendo que, neste último, possuem $\lambda_{\mathrm{kjl}}$ igual a um. As nascentes móveis também se encontram em k1, mas são 
Tabela 1: Probabilidade associada a cada categoria das variáveis em cada perfil $-\lambda_{\mathrm{kjl} 1}{ }^{*}$

\begin{tabular}{|c|c|c|c|c|c|c|}
\hline Variáveis & Categorias & k1 & k2 & k3 & k4 & k5 \\
\hline \multirow{6}{*}{$\begin{array}{l}\text { MORFOLOGIA DA } \\
\text { NASCENTE }\end{array}$} & Concavidade & 0,93 & 0,00 & 0,00 & 1,00 & 0,00 \\
\hline & Duto & 0,00 & 0,46 & 0,00 & 0,00 & 0,68 \\
\hline & Afloramento & 0,00 & 0,54 & 0,00 & 0,00 & 0,00 \\
\hline & Talvegue & 0,00 & 0,00 & 1,00 & 0,00 & 0,00 \\
\hline & Olho & 0,00 & 0,00 & 0,00 & 0,00 & 0,32 \\
\hline & Cavidade/Intervenção & 0,07 & 0,00 & 0,00 & 0,00 & 0,00 \\
\hline \multirow{3}{*}{ TIPO DE EXFILTRAÇÃO } & Pontual & 0,19 & 0,47 & 1,00 & 0,00 & 1,00 \\
\hline & Múltipla & 0,00 & 0,53 & 0,00 & 0,00 & 0,00 \\
\hline & Difusa & 0,81 & 0,00 & 0,00 & 1,00 & 0,00 \\
\hline \multirow{2}{*}{$\begin{array}{l}\text { EXISTÊNCIA DE } \\
\text { CONTATOS }\end{array}$} & Sim & 0,00 & 1,00 & 0,48 & 1,00 & 0,00 \\
\hline & Não & 1,00 & 0,00 & 0,52 & 0,00 & 1,00 \\
\hline \multirow{3}{*}{$\begin{array}{l}\text { VAZÃO MÉDIA ANUAL } \\
(\mathbf{L} / \mathbf{s})\end{array}$} & Menor que 0,056 & 0,70 & 0,25 & 1,00 & 0,83 & 0,34 \\
\hline & $0,057-0,347$ & 0,14 & 0,40 & 0,00 & 0,17 & 0,66 \\
\hline & $0,348-1,400$ & 0,16 & 0,35 & 0,00 & 0,00 & 0,00 \\
\hline \multirow{4}{*}{$\begin{array}{c}\text { RAZÃO DE VAZÃo (verão/ } \\
\text { inverno) }\end{array}$} & Menor que 0,7377 & 0,00 & 0,55 & 0,00 & 0,00 & 0,00 \\
\hline & $0,7378-1,1504$ & 0,46 & 0,21 & 0,00 & 0,61 & 0,00 \\
\hline & $1,1505-8,0000$ & 0,29 & 0,23 & 0,00 & 0,39 & 0,00 \\
\hline & Acima de 8,0000 & 0,24 & 0,00 & 1,00 & 0,00 & 1,00 \\
\hline \multirow{3}{*}{ MIGRAÇÃO } & Não mensurável & 0,00 & 0,00 & 1,00 & 0,00 & 1,00 \\
\hline & Fixa & 0,53 & 1,00 & 0,00 & 0,00 & 0,00 \\
\hline & Móvel & 0,47 & 0,00 & 0,00 & 1,00 & 0,00 \\
\hline \multirow{3}{*}{$\begin{array}{c}\text { PROFUNDIDADE } \\
\text { MÉDIA DO MANTO DE } \\
\text { INTEMPERISMO }(\mathrm{cm})\end{array}$} & $0-11$ & 0,00 & 1,00 & 0,00 & 0,00 & 0,00 \\
\hline & $12-49$ & 0,00 & 0,00 & 1,00 & 1,00 & 0,25 \\
\hline & Acima de 50 & 1,00 & 0,00 & 0,00 & 0,00 & 0,75 \\
\hline \multirow{3}{*}{$\begin{array}{l}\text { POSIÇÃO DOS } \\
\text { AFLORAMENTOS } \\
\text { ROCHOSOS }\end{array}$} & Jusante ou Montante & 0,00 & 0,14 & 0,53 & 0,48 & 0,00 \\
\hline & Na nascente & 0,00 & 0,86 & 0,47 & 0,00 & 0,00 \\
\hline & Não há & 1,00 & 0,00 & 0,00 & 0,52 & 1,00 \\
\hline \multirow{2}{*}{ SAZONALIDADE } & Perene & 1,00 & 1,00 & 0,00 & 1,00 & 0,00 \\
\hline & Intermitente & 0,00 & 0,00 & 1,00 & 0,00 & 1,00 \\
\hline
\end{tabular}

Fonte: Output do programa GoM 3.4.

* Os valores mais elevados encontram-se destacados em cinza, para facilitar a caracterização dos perfis.

exclusivas em k4. Por fim, as nascentes de migração não mensurável estão associadas à $\mathrm{k} 3 \mathrm{e} \mathrm{k} 5$, em ambos os casos, são as únicas presentes em cada um desses perfis.

A profundidade do manto de intemperismo também apresentou uma distribuição de suas categorias bastante eficiente. As nascentes em mantos rasos somente se enquadraram em $\mathrm{k} 2$, sendo exclusivas a esse perfil. As nascentes com profundidade mediana do manto de intemperismo foram alocadas em $\mathrm{k} 3, \mathrm{k} 4$ e $\mathrm{k} 5$, porém, nos dois primeiros, apresentaram $\lambda_{\mathrm{kjl}}$ igual a um. Por fim, as nascentes em mantos profundos representam bem $\mathrm{k} 1$ e k5, $\operatorname{com} \lambda_{\text {kil }}$ altos em ambos os casos.

Quanto à posição dos afloramentos rochosos, nascentes que possuem afloramentos a montante ou à jusante da exfiltração foram enquadradas nos perfis $\mathrm{k} 2$, $\mathrm{k} 3$, e k4, porém, sem $\lambda_{\mathrm{kj} 1}$ elevados. Já as nascentes que possuem afloramentos no local de exfiltração explicam satisfatoriamente $\mathrm{k} 2$ e ainda são inseridas, com menor probabilidade, em $\mathrm{k} 3$. As nascentes que não possuem afloramentos são exclusivas em k1 e k5, além de constituírem, também, $\mathrm{k} 4$.

A variável de sazonalidade foi a mais bem ex- 
plicada, evidenciando sua importância estatística na formação de tipologias de nascente. Não houve inserção parcial, de modo que cada perfil gerado somente é constituído por uma categoria de sazonalidade. Destarte, as nascentes perenes foram inseridas em $\mathrm{k} 1, \mathrm{k} 2 \mathrm{e} \mathrm{k} 4 \mathrm{e}$ as nascentes intermitentes enquadraram-se em $\mathrm{k} 3$ e $\mathrm{k} 5$, em todos os casos, com $\lambda_{\text {kjl }}$ igual a um.

Interpretando a capacidade de explicação de cada um dos tipos criados isoladamente, percebe-se que todos obtiveram resultados satisfatórios. Utilizou-se, para tanto, a interpretação da distribuição dos $\mathrm{g}_{\mathrm{ik}}$ de todas as nascentes nos perfis. Quando o $\mathrm{g}_{\mathrm{ik}}$ é igual a um ou zero, o caso está completamente inserido ou excluído, respectivamente, do perfil. Essa é a configuração mais simples para a explicação da tipologia. Assim, pode-se utilizar o raciocínio da matemática clássica.

A Tabela 2 apresenta a distribuição dos $g_{\text {ik }}$ pelos perfis criados. Considerando-se o percentual de casos com $\mathrm{g}_{\mathrm{ik}}$ igual a um ou zero, pode-se afirmar que todos os tipos são úteis. Aquele que apresentou a menor porcentagem desses casos foi $\mathrm{k} 2$, com $65,7 \%$, o que é considerado plenamente satisfatório. Em todos os outros tipos, esse percentual superou $70 \%$.

\begin{tabular}{|c|c|c|c|c|c|c|c|c|c|c|}
\hline \multirow{2}{*}{$\mathbf{g}_{\mathrm{ik}}$} & \multicolumn{2}{|c|}{ k1 } & \multicolumn{2}{|c|}{ k2 } & \multicolumn{2}{|c|}{ k3 } & \multicolumn{2}{|c|}{ k4 } & \multicolumn{2}{|c|}{ k5 } \\
\hline & Ereq. & $\%$ & Ereq. & $\%$ & Freq. & $\%$ & Freq. & $\%$ & Freq. & $\%$ \\
\hline $\mathbf{0 , 0 0}$ & 45 & $64,3 \%$ & 35 & $50,0 \%$ & 48 & $68,6 \%$ & 46 & $65,7 \%$ & 55 & $78,6 \%$ \\
\hline $0,01-0,34$ & 8 & $11,4 \%$ & 11 & $15,7 \%$ & 10 & $14,3 \%$ & 12 & $17,1 \%$ & 4 & $5,7 \%$ \\
\hline $0,35-0,69$ & 7 & $10,0 \%$ & 9 & $12,9 \%$ & 8 & $11,4 \%$ & 4 & $5,7 \%$ & 3 & $4,3 \%$ \\
\hline $0,70-0,99$ & 0 & $0,0 \%$ & 4 & $5,7 \%$ & 0 & $0,0 \%$ & 2 & $2,9 \%$ & 2 & $2,9 \%$ \\
\hline 1,00 & 10 & $14,3 \%$ & 11 & $15,7 \%$ & 4 & $5,7 \%$ & 6 & $8,6 \%$ & 6 & $8,6 \%$ \\
\hline Total* & 70 & $100 \%$ & 70 & $100 \%$ & 70 & $100 \%$ & 70 & $100 \%$ & 70 & $100 \%$ \\
\hline
\end{tabular}

Os resultados evidenciados na Tabela 2 demonstram que além do modelo estar bem ajustado aos casos, os próprios perfis criados são representativos e não são redundantes. Apesar de alguns possuírem características em comum, de uma forma geral, podem representar com propriedade agrupamentos de nascentes com similaridades internadas e heterogeneidade externa. $\mathrm{Ou}$ seja, enquanto as nascentes de um mesmo tipo possuem semelhanças quanto às suas características e dinâmica, comparadas com as de outro tipo, a diversidade é evidente. É justamente essa propriedade que se espera de uma tipologia.

Desse modo, definido o modelo a ser utilizado, é imprescindível que se busque traduzir a linguagem estatística. O Quadro 1 apresenta uma síntese dos resultados obtidos, juntamente com a proposta de nomenclatura para os seis tipos criados (cinco pelo GoM e um a priori). É importante ressaltar que, por ter sido originada de um método baseado na Teoria dos Conjuntos Nebulosos, a tipologia permite uma infinidade de intercessões entre os perfis e inserções parciais. Por isso, os tipos criados não são excludentes.
As nascentes freáticas possuem como característica principal uma dinâmica resultante da variação do nível freático. Por isso, a vazão média anual é baixa e tende a diminuir no inverno, fruto da redução da recarga. Como a exfiltração ocorre pela interceptação do nível freático pela superfície, essas nascentes são prioritariamente difusas, ocorrendo em concavidades no relevo que permitem esse contato com a água subterrânea.

As nascentes dinâmicas caracterizam-se, mormente, pela alta energia dos processos que a constituem, sendo perenes e as únicas representadas por alta vazão. Seus fluxos subterrâneos são estáveis a ponto de, no inverno, a vazão tender a aumentar, resultado da convergência de outros fluxos que, no verão, eram independentes e alimentavam outras nascentes. São originadas por superfícies de impermeabilização, com presença de afloramentos rochosos em mantos rasos. Sua exfiltração é pontual ou múltipla, mas nunca difusa, o que é explicado pela morfologia que apresentam (afloramento ou duto).

As nascentes sazonais erosivas são caracterizadas pela interceptação sazonal do nível freático por feições 
Quadro 2: Características relacionadas a cada perfil criado pelo GoM e proposta de nomenclatura para os tipos.

\begin{tabular}{|c|c|c|c|c|c|c|}
\hline TIPO & k1 & k2 & k3 & k4 & k5 & k6 \\
\hline Morfologia & Concavidade & $\begin{array}{l}\text { Afloramento ou } \\
\text { duto }\end{array}$ & Talvegue & Concavidade & Duto ou olho & - \\
\hline Tipo de exfiltração & Difusa & $\begin{array}{l}\text { Múltipla ou } \\
\text { pontual }\end{array}$ & Pontual & Difusa & Pontual & - \\
\hline $\begin{array}{c}\text { Existência } \\
\text { de contato } \\
\text { estratigráfico }\end{array}$ & Sem contato & Com contato & Indiferente & Com contato & Sem contato & - \\
\hline Vazão média anual & Baixa & Indiferente & Baixa & Baixa à média & Média à baixa & - \\
\hline Razão de vazão & $\begin{array}{l}\text { Prioritariamente } \\
\text { estável, tendendo } \\
\text { a superior a } 1\end{array}$ & $\begin{array}{l}\text { Prioritariamente } \\
\text { inferior a } 1\end{array}$ & Muito elevada & $\begin{array}{l}\text { Prioritariamente } \\
\text { estável, tendendo } \\
\text { a superior a } 1\end{array}$ & Muito elevada & - \\
\hline Migração & Indiferente & Fixa & $\begin{array}{c}\text { Não } \\
\text { mensurável }\end{array}$ & Móvel & $\begin{array}{c}\text { Não } \\
\text { mensurável }\end{array}$ & - \\
\hline $\begin{array}{c}\text { Prof. média } \\
\text { do manto de } \\
\text { intemperismo }\end{array}$ & Profundo & Raso & Médio & Médio & Profundo & - \\
\hline $\begin{array}{l}\text { Posição dos } \\
\text { afloramentos } \\
\text { rochosos }\end{array}$ & Ausente & Na nascente & $\begin{array}{l}\text { Existente (na } \\
\text { nascente ou } \\
\text { arredores) }\end{array}$ & $\begin{array}{l}\text { Ausente ou } \\
\text { arredores }\end{array}$ & Ausente & - \\
\hline Sazonalidade & Perene & Perene & Intermitente & Perene & Intermitente & - \\
\hline Nome & Freática & Dinâmica & $\begin{array}{l}\text { Sazonal } \\
\text { erosiva }\end{array}$ & Flutuante & $\begin{array}{l}\text { Sazonal de } \\
\text { encosta }\end{array}$ & Antropogênica \\
\hline
\end{tabular}

Fonte: Elaboração do autor

erosivas, sobretudo, talvegues de ravinas ou taludes de canais de drenagem. Por serem alimentadas pelo nível freático mais raso e extremamente dependente dos eventos chuvosos, são intermitentes e de baixa vazão.

As nascentes flutuantes são originadas pelo nível freático flutuante ao longo do ano, o que promove a migração da nascente na vertente, normalmente com exfiltração resultante de contatos da rocha com o manto de intemperismo. Assim como as nascentes freáticas, são caracterizadas morfologicamente por concavidades e a exfiltração é difusa, porém, os mantos de intemperismo não são profundos, o que possibilita a formação de uma superfície impermeável que viabiliza a exfiltração à jusante com o rebaixamento do nível freático.
As nascentes sazonais de encosta possuem a peculiaridade de localizarem-se em encostas com mantos de intemperismo profundos e serem intermitentes. Tendem a estar associadas a níveis freáticos com marcante flutuação entre os períodos de chuva e seca e, como não possuem anteparos de impermeabilização próximos à superfície, a exfiltração cessa. Entretanto, no verão a energia de suas águas é relativamente elevada, o que pode ser observado pela morfologia (dutos ou olhos) e tipo de exfiltração (pontual).

Por fim, as nascentes antropogênicas devem ser consideradas como uma categoria à parte, já que sua principal característica é ter sido originada por intervenção humana. Em outras palavras, isso significa que 
não estão associadas a condições naturais favoráveis à gênese de uma nascente, porém, as ações humanas desencadearam processos que levaram à exfiltração. Em determinadas situações, a identificação de uma nascente como antropogênica pode ser extremamente complexa, devido à ausência de informações sobre o quadro anterior à intervenção. Desse modo, as nascentes antropogênicas podem possuir qualquer característica dos demais tipos.

\subsection{Enquadramento das nascentes nos tipos criados}

Uma tipologia baseada na Teoria dos Conjuntos Nebulosos possibilita que uma nascente se enquadre simultaneamente a diversos perfis. Assim, é necessário interpretar $\mathrm{o}_{\mathrm{ik}}$ em cada uma das unidades de estudo. $\mathrm{O}$ Gráfico 1 facilita esse entendimento. Há uma predominância de $\mathrm{g}_{\mathrm{ik}}$ elevados para $\mathrm{k} 1$ e k2 - nascentes freáticas e nascentes dinâmicas, respectivamente. Além disso, muitas nascentes são pertencentes a três tipos diferentes, havendo inclusive um caso com pertencimento a quatro tipos - N073.
Os casos em que a associação do grau de pertinência a dois perfis distintos foi superior a 0,70 , foram considerados híbridos e tematizados de acordo com a intercessão ocorrida. Com isso, além dos seis tipos padrões criados - freática, dinâmica, sazonal erosiva, flutuante, sazonal de encosta e antropogênica - possibilitou-se a existência de tipos híbridos formados por pares de tipos padrões: freática-dinâmica, freática-erosiva, freática-flutuante, freática-de encosta, dinâmica-erosiva, dinâmica-flutuante, flutuante-erosiva, sazonal erosiva-de encosta.

Consciente da diversidade das nascentes, inclusive no interior dos tipos criados, pode-se então promover o enquadramento das unidades de estudo naqueles perfis de maior afinidade, sejam eles padrões ou híbridos. As nascentes que não possuem características dominantes de algum perfil - no caso, quando a soma dos dois maiores $g_{\mathrm{ik}}$ de determinado caso é inferior a 0,70 - não pode ser enquadrada na tipologia adotada, sendo considerada nebulosa.

A leitura do Gráfico 2 permite afirmar que há um predomínio dos tipos padrões, que, somados, detêm

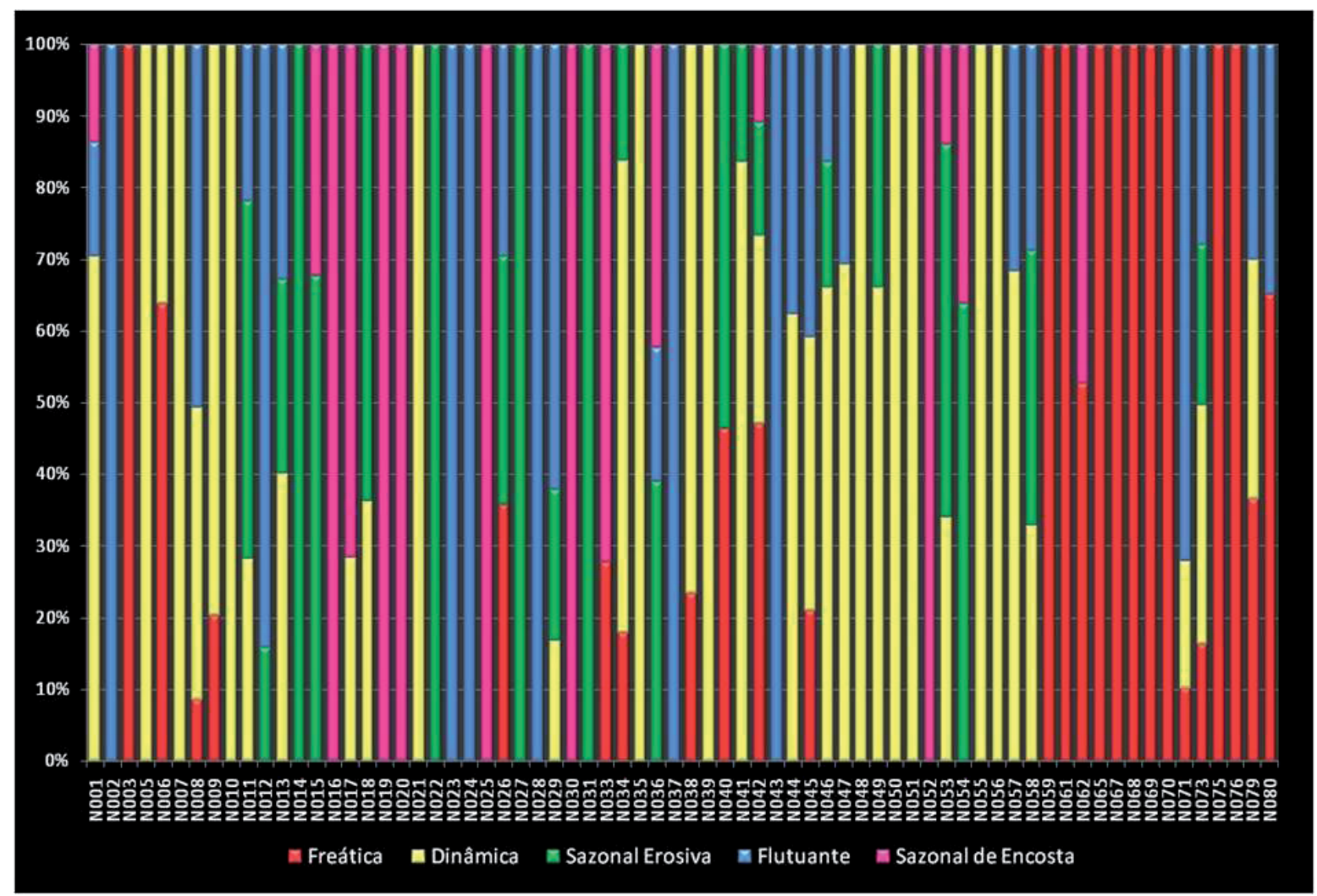

Gráfico 1: Distribuição percentual dos graus de pertinência das nascentes a cada tipo. 
$68,4 \%$ dos casos. As nascentes nebulosas constituem apenas $2,5 \%$ de todo o rol. Os demais $29,1 \%$ das nascentes enquadram-se nos tipos híbridos, com destaque para as dinâmicas-erosivas e dinâmicas-flutuantes. Percebe- -se um predomínio das características das nascentes dinâmicas mesmo naquelas que se enquadram em tipos híbridos, o que comprova que este tipo de nascente é a mais comum nas unidades de estudo trabalhadas.

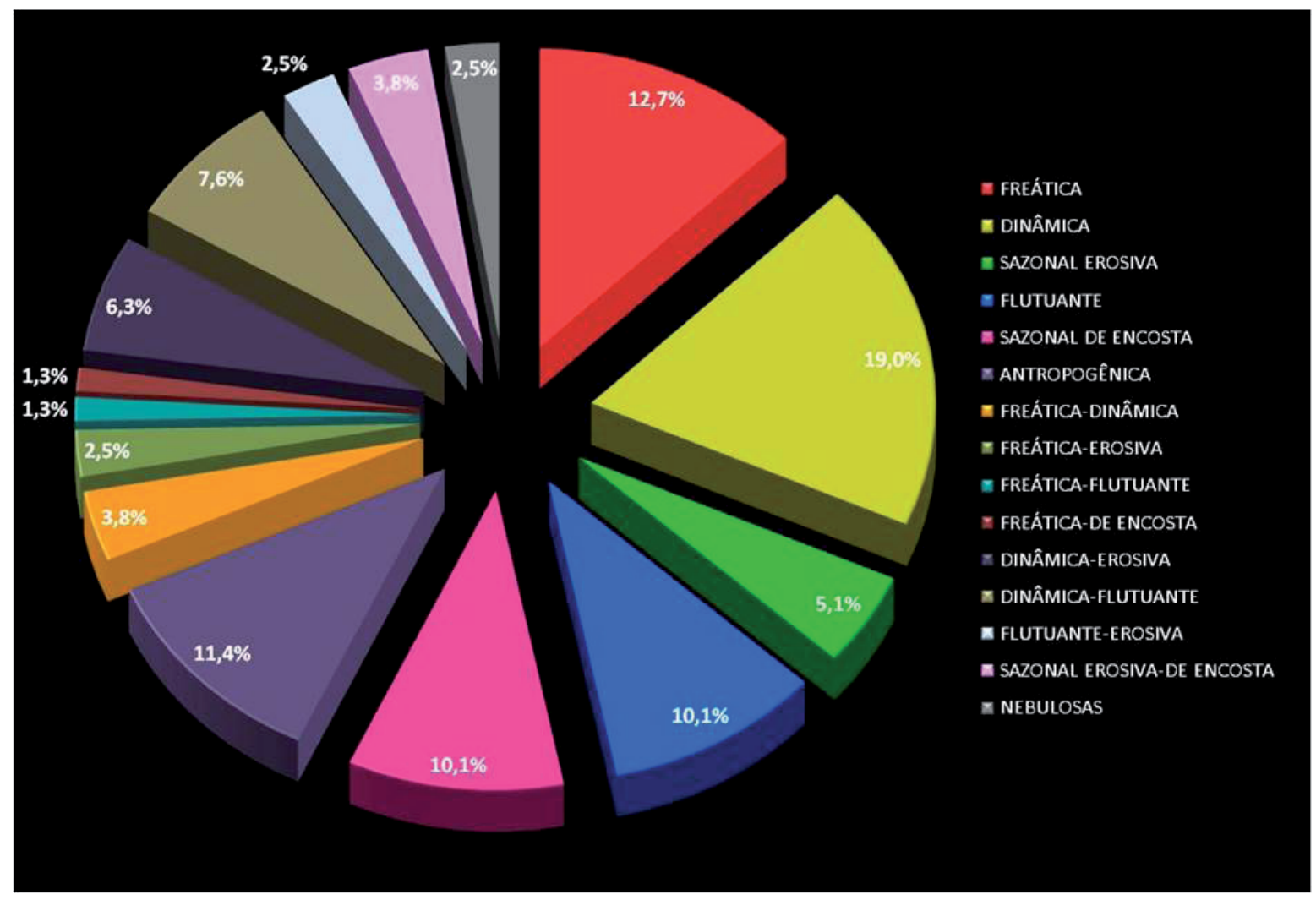

Gráfico 2: Distribuição percentual das nascentes estudadas por tipo.

Essa assertiva fica evidente com a espacialização dos dados na Figura 2. O Parque das Mangabeiras, unidade estudada com maior número de nascentes, possui uma clara predominância de nascentes dinâmicas e de tipos híbridos com características dinâmicas. O Parque Lagoa do Nado caracteriza-se por uma grande presença de nascentes antropogênicas, com importante participação das freáticas ou freáticas-de encosta. Já no Parque Primeiro de Maio a maioria das nascentes enquadrou-se como freática.

Analisando os resultados para os Parques Primeiro de Maio e Lagoa do Nado, pode-se afirmar que ambos possuem nascentes tipologicamente muito semelhantes. Destarte, ambos os parques encontram-se em um mesmo contexto geológico-geomorfológico, caracterizado pela Depressão de Belo Horizonte com profundos mantos de intemperismo no embasamento cristalino granito-gnáissico-migmatítico. Por outro lado, o Parque das
Mangabeiras está localizado na Serra do Curral, embasado por rochas metassedimentares do Supergrupo Minas, com mantos de intemperismo muito rasos. Consequentemente, suas nascentes apresentaram tipologias completamente diferentes daquelas verificadas nos outros dois parques.

Nesse sentido, os resultados obtidos dessa classificação podem ser de grande utilidade na gestão dos recursos hídricos, em consonância com a Lei Federal 9.433/1997. Quanto ao novo Código Florestal, Lei Federal 12.651/2012, (que coloca as premissas para a proteção das nascentes a partir do estabelecimento de Áreas de Preservação Permanente), independentemente do tipo de nascente, todas devem ser vistas da mesma forma sob os olhos da lei. A única distinção feita na Lei Federal 12.651/2012 está relacionada à sazonalidade das fontes, onde, aquelas que não são perenes não são denominadas nascentes, mas sim, "olhos d'água”. Ain- 

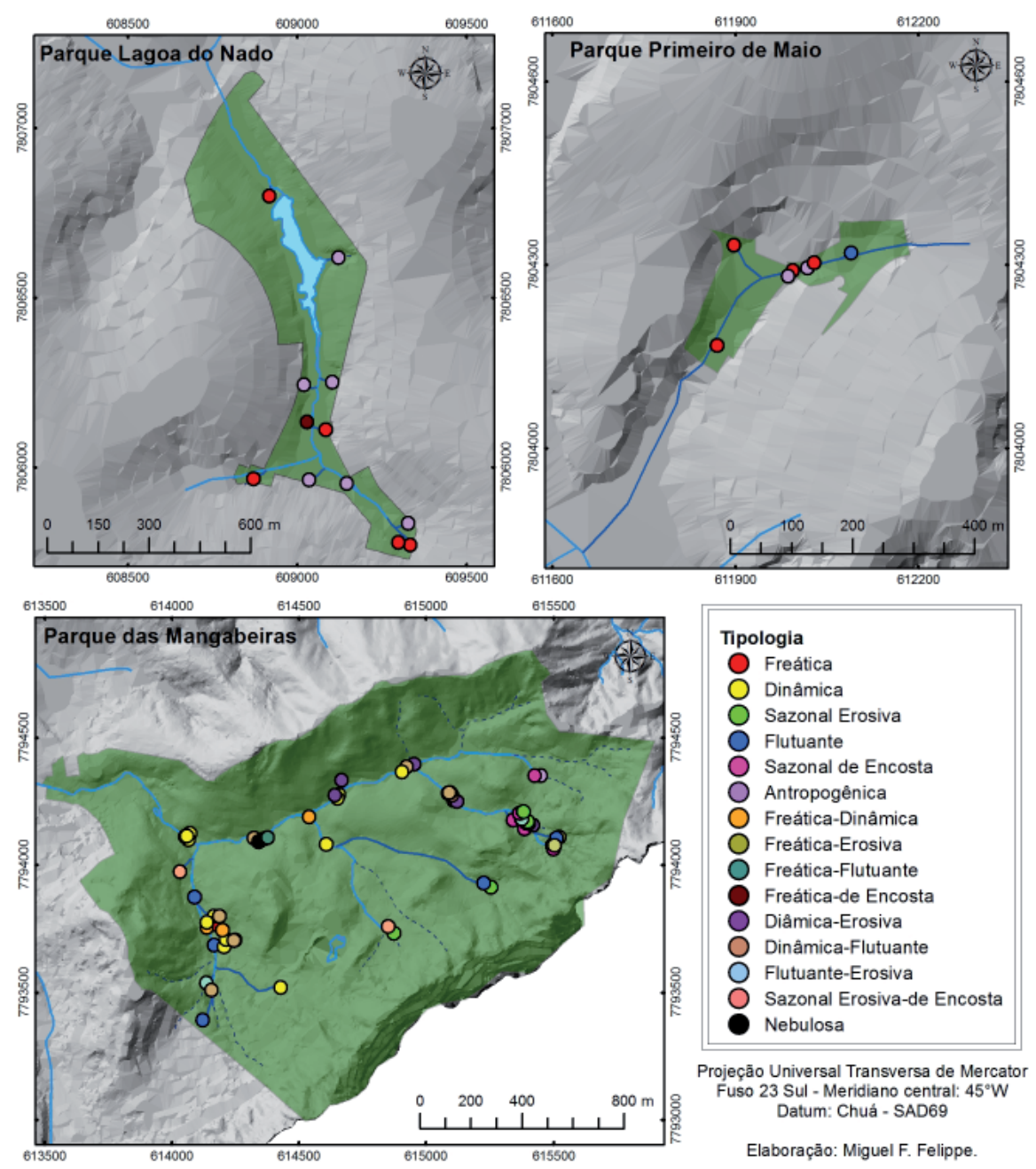

Figura 2: Espacialização da tipologia das nascentes estudadas

da assim, as premissas de proteção são mantidas para ambos os conceitos (50 metros de raio de preservação).

Contudo, no que tange à aplicabilidade da classificação proposta na Política Nacional de Recursos Hídricos e na Política Nacional de Meio Ambiente, a tipologia das nascentes realizadas em bacias hidrográficas tomadas como unidades de gestão auxiliará na identificação das potencialidades e vulnerabilidades ambientais, assumindo que nascentes de tipos diferentes demandam manejos distintos para a manutenção de sua qualidade.

\section{Conclusões}

A metodologia inovadora proposta neste trabalho demonstrou-se plenamente satisfatória ao responder os questionamentos levantados com rigor científico. Foi possível desenvolver um encadeamento de procedimentos que, levou ao estabelecimento de seis perfis básicos nos quais foram enquadradas as 79 nascentes estudadas. Apesar da heterogeneidade fisiográfica das três áreas de estudo, o ajuste do modelo foi confiável, criando condições para sua replicação em outros contextos hidrogeomorfológicos. O relativamente pequeno número de variáveis utilizadas na proposta final (nove) facilita que esses procedimentos possam ser desenvolvidos nos mais diversos contextos. Além disso, há a possibilidade de substituição de certas variáveis por outras mais adequadas a cada estudo. Quanto à replicação em outras escalas de análise, o único fator de dificuldade deve ser o de mapeamento das nascentes, que demanda severos esforços de campo, sobretudo em áreas de estudo maiores. Contudo, esse é um problema inerente a qualquer pesquisa relacionada à temática das nascentes. 
Parece claro, após o mapeamento da tipologia proposta, que há um nítido condicionante espacial para a determinação do tipo das nascentes. Enquanto predominaram nascentes dinâmicas nas áreas de contexto serrano, as nascentes freáticas foram mais comuns na depressão. Emerge como resposta, em princípio, o contexto geológico-geomorfológico regional, com especial importância para a profundidade do manto de intemperismo. Ressalta-se que a matriz qualitativa utilizada na elaboração da tipologia pelo GoM não apresentava quaisquer características em escala regional, o que inviabiliza o contra-argumento de que esse condicionante seria um resultado falacioso do método utilizado.

Contudo, faz-se necessária a aplicação da proposta em outros contextos ambientais para confirmar sua efetividade enquanto um modelo genérico para tipologia de nascentes. Não obstante, o método estatístico é flexível a eventuais ajustes nas variáveis analisadas, bem como em suas categorizações, podendo ser adaptado a quaisquer áreas do globo.

Espera-se que esse novo olhar sobre as nascentes contribua para a gestão dos recursos hídricos, uma vez que a enorme heterogeneidade desses sistemas dificulta a adoção de métodos de conservação universais. Agrupando-as em perfis de máxima verossimilhança, porém, será possível desenvolver técnicas de manejo adequadas a cada tipo de nascente sem, contudo, minimizar suas idiossincrasias.

\section{Agradecimentos}

Ao CNPq e à FAPEMIG pelo apoio financeiro ao projeto; ao grupo de pesquisa Geomorfologia e Recursos Hídricos do Instituto de Geociências da UFMG; ao Laboratório de Geomorfologia do Instituto de Geociências da UFMG; à Fundação de Parques Municipais da Prefeitura de Belo Horizonte; à gerência e aos funcionários dos parques das Mangabeiras, Lagoa do Nado e Primeiro de Maio.

\section{Referências}

AlVES, L. C.; LEITE, I. C.; MACHADO, C. J. Perfis de saúde dos idosos no Brasil: análise da Pesquisa Nacional por Amostra de Domicílios de 2003 utilizando o método Grade of Membership. Cad. Saúde Pública, Rio de Janeiro, 24(3), 2008. pp. 535-546.
CERQUEIRA, C. A. Tipologia e características dos estabelecimentos escolares brasileiros. Tese (doutorado). Universidade Federal de Minas Gerais, 2004.

CHRISTOFOLETTI, A. Geomorfologia fluvial. São Paulo: E. Blucher: Fundação de Amparo a Pesquisa do Estado de São Paulo, 1981.

CPRM - SERVIÇO GEOLÓGICO DO BRASIL. Carta geológica de Belo Horizonte. Escala 1:100.000. CPRM, 2000.

FARIA, A. P. A dinâmica de nascentes e a influência sobre os fluxos nos canais. A Água em Revista, Rio de Janeiro, v. 8, p. 74-80, 1997.

FELIPPE, M. F.; MAGALHAES JR., A. P.; GARCIA, R. Tipologia e classificação das zonas preferenciais de recarga de aquíferos em Belo Horizonte-MG: aplicação do método grade of membership (GoM). Boletim de Geografia (UEM), v. 31, p. 101-114, 2013.

FELIPPE, M. F.; MAGALHAES JR., A. P.; GARCIA, R.. Utilização do método Grade of Membership (GoM) na classificação da eficiência ambiental de zonas de recarga de aquíferos em Belo Horizonte-MG. In: XVIII Simpósio Brasileiro de Recursos Hídricos, 2009, Campo Grande - MS. Anais do... Campo Grande: ABRH, 2009.

FELIPPE, M.F. Caracterização e tipologia de nascentes em unidades de conservação de Belo Horizonte com base em variáveis geomorfológicas, hidrológicas e ambientais. Dissertação (mestrado). Universidade Federal de Minas Gerais, Instituto de Geociências, 2009.

GARCIA, R. A; SOARES-FILHO, B.; SAWYER, D. O. Dimensões sócio-econômicas e movimentos populacionais: uma regionalização da Amazônia brasileira In: XIV Encontro Nacional de Estudos Populacionais, Caxambu. Anais do... Caxambu: ABEP, 2004.

GOMES, P. M. ; MELO, C. ; VALE, V. S. . Avaliação Microbiológica e Físico-química em Nascentes na Cidade de Uberlândia - MG. In: VII Congresso de Ecologia do Brasil, 2005, Caxambu/MG. Anais do..., 2005a.

HARRIS, A.L.N.C. Metodologias baseadas na Teoria dos Sistemas Nebulosos (Fuzzy Systems Theory) para o tratamento das informações subjetivas do Projeto Arquitetônico. Tese (Doutorado). Universidade de São Paulo, 1999.

IBGE - INSTITUTO BRASILEIRO DE GEOGRAFIA E ESTATÍSTICA. Mapa de unidades de relevo do Brasil. Escala 1:5.000.000. IBGE, 2006. 
MANTON, K., WOODBURY, M., TOLLEY, D. Statistical applications using fuzzy sets. [s.1.]: Wiley, 1994.

MEINZER, O.E. Large springs in the United States. U.S. Geological Survey Water-Supply Paper 557. Washington D.C. 1927.

PASSOS, M. M. dos. Biogeografia e paisagem. [s.1.]: [s.n.], 1998.

PINTO, L. V. A.; BOTElHo, S. A.; DAVIDE, A. C.; FERREIRA, E. Estudo das nascentes da bacia hidrográfica do Ribeirão Santa Cruz, Lavras, MG. Scientia Forestalis. N ${ }^{\circ} 65$. jun. 2004. p. 197-206

SANTOS, R. D.; LEMOS, R. C.; SANTOS, H. G.; Ker, J. C.; ANJOS, L. H. C. Manual de descrição e coleta de solo no campo. $5^{\text {a }}$ ed. Viçosa: Sociedade Brasileira de Ciência de Solo, 2005.

SATHLER, D. As redes para além dos rios: urbanização e desequilíbrios na Amazônia Brasileira. Tese (doutorado). Universidade Federal de Minas Gerais, Centro de Desenvolvimento e Planejamento Regional, 2009.

SCHOBBENHAUS, C. Geologia do Brasil: texto explicativo do mapa geológico do Brasil e da área oceânica adjacente incluindo depósitos minerais. Brasília: Dep. Nacional da Produção Mineral, 1984.

SILVA, A.; CARVALHO, E. T.; FANTINEL, L. M.; ROMANO, A. W.; VIANA, C. S. Estudos geológicos, hidrogeológicos, geotécnicos e geoambientais integrados no município de Belo Horizonte: projeto estudos técnicos para o levantamento da carta geológica do município de Belo Horizonte; relatório final. Belo Horizonte: FUNDEP/UFMG-IGC, 1995.

TODD, D. K. Hidrologia de águas subterrâneas. São Paulo: E. Blucher, 1959.

TROPPMAIR, H. Biogeografia e meio ambiente. $6^{\mathrm{a}}$ ed. Rio Claro: Divisa, 2004.

VALENTE, O. F.; GOMES, M. A. Conservação de nascentes: hidrologia e manejo de bacias hidrográficas de cabeceiras. Viçosa: Aprenda Fácil, 2005. 